\title{
Contenido de Polifenoles totales y capacidad antioxidante en cervezas artesanales e industriales
}

\author{
Content total polyphenolics and antioxidant capacity in craft and industrial beers
}

\author{
J.C.Pachas ${ }^{1}$
}

\begin{abstract}
Resumen
Objetivos: Determinar el contenido de polifenoles y la capacidad antioxidante de algunos tipos de cervezas artesanales e industriales. Metodología: Se utilizaron un total de diez tipos de cerveza, dos de origen industrial y ocho del tipo artesanal que se expenden y se consumen con mayor frecuencia en la provincia de Huaral, LimaPerú. El contenido de polifenoles totales se realizó por el método Folin Ciocalteu y la capacidad antioxidante por el método del radical libre 2,2-diphenyl-1-picrylhydrazyl DPPH, utilizando un espectrofotómetro UV-Visible. Para el análisis de los datos, el análisis de la varianza de un diseño completamente al azar y la prueba de ScottKnott para la comparación de medias fueron utilizados. Resultados: El promedio de polifenoles totales (0,96 vs. $\left.0,53 \mathrm{mg} \mathrm{EAG} \mathrm{mL}^{-1}\right)$ y la capacidad antioxidante $\left(3,63 \mathrm{vs} .1,16 \mu \mathrm{Mol} \mathrm{DPPH} \mathrm{mL} \mathrm{m}^{-1}\right)$ fueron mayores en las cervezas artesanales en comparación a las industriales $(P<0,05)$. Conclusiones: Las cervezas artesanales contienen mayor concentración de polifenoles y poseen mayor capacidad antioxidante que las cervezas industriales.
\end{abstract}

Palabras clave: Cerveza artesanal, polifenoles, capacidad antioxidante

\begin{abstract}
Objectives: To determine the content of polyphenols and the antioxidant capacity of some types of craft and industrial beers. Methodology: A total of ten types of beer were used, two of industrial origin and eight of the artisanal type that are sold and consumed more frequently in the province of Huaral, Lima-Peru. The content of total polyphenols was made by the Folin Ciocalteu method and the antioxidant capacity by the free radical method 2,2-diphenyl-1-picrylhydrazyl DPPH, using a UV-Visible spectrophotometer. For the analysis of the data, the analysis of the variance of a completely randomized design and the Scott-Knott test for the comparison of means were used. Results: The average total polyphenols ( $\left.0.96 \mathrm{vs} .0 .53 \mathrm{mg} \mathrm{EAG} \mathrm{mL}{ }^{-1}\right)$ and the antioxidant capacity (3.63 vs. $1.16 \mu \mathrm{Mol}$ DPPH mL-1) were higher in craft beers compared to industrial beers $(P<0.05)$. Conclusions: Craft beers contain a higher concentration of polyphenols and have greater antioxidant capacity than industrial beers.
\end{abstract}

Keywords: Craft beer, total polyphenol, antioxidant capacity

\section{Introducción}

La cerveza es una de las bebidas alcohólicas más consumidas en todo el mundo, es rica en nutrientes, como carbohidratos, aminoácidos, minerales, vitaminas y antioxidantes fitoquímicos, en los que se incluyen a los compuestos fenólicos (Zapata et al., 2019). La cerveza es una bebida natural tradicional en todo el mundo, con pocas calorías y sin grasa, con ácidos orgánicos y vitaminas (provenientes de la malta), proteínas, lúpulo (un sedante suave y un estimulante del apetito) y agua. La cerveza tiene un valor nutricional más alto que otras bebidas alcohólicas, debido a sus minerales y nutrientes esenciales como potasio, magnesio, calcio y sodio
(Ribeiro et al., 2010).

La cerveza contiene una variedad de polifenoles que pueden ser importantes por su estabilidad química, que incluyen flavonoides prenilados, ácidos fenólicos, fenoles simples, flavanoles, hidroxicumarinas, flavonas, proantocianidinas, taninos y compuestos amino fenólicos. Además de su potencial antioxidante, estos compuestos juegan un papel importante en el sabor (amargura, astringencia, dureza) y color. La mayoría de los compuestos fenólicos se derivan de la malta y el resto proviene del lúpulo. Estos compuestos están involucrados en la estabilidad química y la vida útil de la cerveza. Los compuestos fenólicos también pueden funcionar

${ }^{1}$ Instituto Tecnológico Superior Público Huando, Lima, Perú. e-mail: joelpachasv@gmail.com 
como antioxidantes en el cuerpo humano, como agentes protectores contra la oxidación del ácido ascórbico y los ácidos grasos insaturados (Pai et al., 2015).

Muchas investigaciones proporcionan pruebas sólidas de un efecto cardioprotector del consumo moderado de alcohol (como cerveza o vino) (hasta 2 vasos al día en el caso de los hombres y 1 vaso al día en el caso de mujeres), así como el control del metabolismo de lípidos (colesterol), coagulación sanguínea y metabolismo de la glucosa (Zapata et al., 2019). Mitić et al. (2014) indicaron que los polifenoles de la cerveza además de poseer actividad antioxidante, especialmente frente a los radicales hidroxilo, involucrados en los procesos de peroxidación de lípidos, pueden desempeñar un papel activo en la prevención de la enfermedad de Alzheimer y otros trastornos relacionados.

Koren et al. (2017) manifestaron que además de la cerveza como producto, están también las cervezas mezcladas con jugo de frutas y sus alternativas sin alcohol, indicando que las cervezas artesanales son cada vez más populares. Entre ellas hay muchos tipos diferentes de cerveza elaboradas con ingredientes especiales. Aunque se están volviendo más y más populares, todavía se carece de la información sobre sus componentes y cualidades potencialmente saludables.

En la provincia de Huaral, departamento de Lima, y en otras ciudades del Perú se consumen cervezas del tipo artesanal e industrial, experimentado actualmente un aumento en el consumo de cervezas del tipo artesanal. Las propiedades benéficas de estos tipos de cerveza están poco estudiadas. El objetivo de la investigación fue determinar el contenido de polifenoles y la capacidad antioxidante de algunos tipos de cervezas artesanales en comparación con las cervezas industriales que son comercializadas en la zona.

\section{Metodología}

Reactivos

Todos los reactivos usados son de calidad para análisis, DPPH (Sigma-Aldrich), ácido gálico, metanol (Merck), Folin-Ciocalteu (Merck) y agua des-ionizada (Fravill Modelo DES100 20).

\section{Muestras de Cervezas}

Se adquirieron 10 tipos de cervezas, 02 industriales (A, B) y 08 artesanales (La Candelaria: C1, C2, C3, C4 y C5; Culti Bar: D1 y D2 y Tradiciones Huaralinas: E), procedentes del mercado local y supermercados de la provincia de Huaral, departamento de Lima. Las muestras antes de su análisis fueron estabilizadas a una temperatura de $5^{\circ} \mathrm{C}$ empleando un refrigerador doméstico (Coldex), luego de ser abiertas fueron desgasificadas con un agitador (Dragon laboraty instruments) por espacio de 10 - 15 minutos; se tomaron muestras protegiéndolas de la luz y de inmediato fueron utilizadas para su medición o se almacenaron a $-10^{\circ} \mathrm{C}$ en un refrigerador doméstico. Se realizaron cuatro réplicas por tipo de cerveza para el análisis de polifenoles totales y tres para la actividad antirradical por DPPH.

\section{Contenido de fenoles totales}

Antes de cada análisis, las muestras fueron filtradas. La cuantificación de los fenólicos totales se realizó conforme a la reacción colorimétrica de FolinCiocalteu pero siguiendo la metodología sugerida por Magalhães et al.(2010), empleando un espectrofotómetro de haz simple UV-Vis (UNICO SQ2800). Se realizó una curva de calibración utilizando diferentes concentraciones $\left(0.0-30 \mathrm{mg} \mathrm{L}^{-1}\right)$ de soluciones estándar de ácido gálico, resultando la siguiente ecuación, $\mathrm{Y}=0.019 \mathrm{x}+0.0192, \mathrm{R}^{2}=0.9995$. La concentración de los fenoles totales es expresada como mg de $\mathrm{EAG} / \mathrm{mL}$ de muestra.

\section{Actividad antirradical por DPPH}

El ensayo con el radical libre 2,2-diphenyl-1picrylhydrazyl (DPPH) fue empleado para medir la capacidad antioxidante según el método modificado por Abderrahim et al. (2013), las muestras de cerveza previamente filtradas y diluidas (50 $\mu \mathrm{L}$ muestra o el blanco control) fueron colocadas en una cubeta de cuarzo de $10 \mathrm{~mm}$ por triplicado y se mezclaron con $1000 \mu \mathrm{L}$ de DPPH ( $60 \mu \mathrm{Mol} \mathrm{L}^{-1}$ disuelto en metanol 1: 1/10 $\mathrm{mMol} \mathrm{L}^{-1}$ Tris-HCl buffer $\mathrm{pH} 7,5$ ), después de 10 minutos de incubación a temperatura ambiente, se midió la absorbancia a $520 \mathrm{~nm}$ con un espectrofotómetro de haz simple UV-Vis (UNICO SQ2800). La capacidad antioxidante de la cerveza expresada en $\mu \mathrm{Mol}$ DPPH $\mathrm{mL}^{-1}$ fue calculada utilizando la siguiente expresión:

$$
\mu \mathrm{Mol} \frac{D P P H}{m L}=\frac{\left(A_{0}-A_{t}\right)}{A_{0}} \times \frac{V_{t}[D P P H] \mathrm{x} F D}{m L}
$$

donde,

$A_{0}$, es la absorbancia del control (DPPH diluido en metanol)

$A_{t}$, es la absorbancia con presencia de la muestra

$V_{t}$, es el volumen total de reacción en Litros 
$[D P P H]$, es la concentración del DPPH

$F D$, es el factor de dilución

$m L$, son los mililitros de muestra empleados en la reacción

\section{Resultados y discusión}

La cerveza es una de las principales fuentes de compuestos fenólicos y su presencia contribuye a su sabor, color y propiedades sensoriales. En la Tabla 1 se presenta la determinación de polifenoles totales y capacidad antioxidante de los 10 tipos de cerveza analizados.

\section{Tabla 1}

Polifenoles totales y capacidad antioxidante (promedio \pm desviación estándar) según la procedencia de las cervezas

\begin{tabular}{|c|c|c|c|c|c|}
\hline Procedencia & Marca & $\begin{array}{c}\text { Tipo } \\
\text { Fermentación }\end{array}$ & $\begin{array}{l}\text { Alcohol } \\
(\%)\end{array}$ & $\begin{array}{l}\text { Polifenoles totales } \\
\left(\mathrm{mg} \mathrm{EAG} \mathrm{mL}^{-1}\right)\end{array}$ & $\begin{array}{l}\text { Capacidad antioxidante } \\
\left(\mu \mathrm{Mol} \mathrm{DPPH} \mathrm{mL}^{-1}\right)\end{array}$ \\
\hline \multicolumn{6}{|l|}{ Industrial } \\
\hline & $\mathrm{A}$ & Lager & 4.8 & $0,47 \pm 0,05^{f}$ & $1,18 \pm 0,06^{b}$ \\
\hline & B & Lager & 4.8 & $0,59 \pm 0,04^{f}$ & $1,14 \pm 0,04^{b}$ \\
\hline \multicolumn{6}{|l|}{ Artesanal } \\
\hline & $\mathrm{C} 1$ & Witbier & 6.1 & $0,70 \pm 0,08^{c}$ & $3,63 \pm 0,19^{a}$ \\
\hline & $\mathrm{C} 2$ & Red ale & 6.1 & $0,99 \pm 0,09^{c}$ & $3,66 \pm 0,45^{a}$ \\
\hline & $\mathrm{C} 3$ & Moche loche & 6.1 & $0,74 \pm 0,07^{e}$ & $3,84 \pm 0,08^{a}$ \\
\hline & $\mathrm{C} 4$ & Golden ale & 6.1 & $1,33 \pm 0,09^{a}$ & $3,63 \pm 0,28^{a}$ \\
\hline & $\mathrm{C} 5$ & Lager dorada & 6.1 & $0,84 \pm 0,07^{d}$ & $3,83 \pm 0,13^{a}$ \\
\hline & D1 & Pale Ale & 5.5 & $0,85 \pm 0,07^{d}$ & $3,58 \pm 0,13^{a}$ \\
\hline & D2 & Lager & 5.5 & $0,98 \pm 0,08^{c}$ & $3,54 \pm 0,43^{a}$ \\
\hline & $\mathrm{E}$ & Lager & 5.2 & $1,14 \pm 0,05^{b}$ & $3,23 \pm 0,17^{a}$ \\
\hline
\end{tabular}

\footnotetext{
${ }^{\text {a-f }}$ Letras distintas en una misma columna indican diferencia estadística $(P<0,05)$.
}

En la determinación de los polifenoles totales, se observó que las cervezas industriales tuvieron un promedio de $0,53 \mathrm{mg} \mathrm{EAG} / \mathrm{mL}$, mientras que las cervezas artesanales $0,96 \mathrm{mg}$ EAG $\mathrm{mL}^{-1}$. Los resultados indicaron que las cervezas de elaboración industrial tienen un menor contenido de polifenoles totales que las cervezas de elaboración artesanal. Las cervezas artesanales mostraron un rango de polifenoles totales que va de 0,70 a $1,33 \mathrm{mg}$ EAG $\mathrm{mL}^{-1}$. Estos valores fueron superiores a los reportados por Mitić et al. (2013) en cervezas industriales de Serbia $(0,328-$

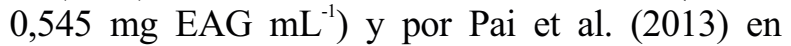
cervezas de la India $\left(0,16-0,62 \mathrm{mg}\right.$ EAG $\left.\mathrm{mL}^{-1}\right)$. En relación a la capacidad de secuestro de los radicales libres por el DPPH, las cervezas artesanales obtuvieron un promedio de $3,63 \mu \mathrm{Mol} \mathrm{DPPH} \mathrm{mL}^{-1}$, mientras que las cervezas industriales $1,16 \mu \mathrm{Mol}$ $\mathrm{DPPH} \mathrm{mL}{ }^{-1}$. Se aprecia una marcada diferencia entre las procedencias, lo que nos indica que las cervezas artesanales son las que poseen mayor capacidad antioxidante. En cervezas industriales, Mitić et al.
(2013) indicaron valores de 0,56 a 1,66 $\mu \mathrm{Mol} \mathrm{DPPH}$ $\mathrm{mL}^{-1}$, que fueron inferiores a lo hallado en las cervezas artesanales en este estudio. El mayor contenido de polifenoles y capacidad antioxidante de las cervezas artesanales dan a ésta propiedades que beneficiarían la salud del consumidor, como lo mencionan Zapata et al. (2019).

\section{Conclusiones}

Las cervezas artesanales contienen mayor concentración de polifenoles y poseen una mayor capacidad antioxidante que las cervezas industriales.

\section{Referencias}

Abderrahim, F., Arribas, S. M., Gonzalez, M. C. \& Condezo-Hoyos, L. (2013). Rapid highthroughput assay to assess scavenging capacity index using DPPH. Food Chemistry, 141(2), 788-794. 
Koren, D., Orbán, C., Galló, N., Kun, S., VecseriHegyes, B. \& Kun-Farkas, G. (2017). Folic acid content and antioxidant activity of different types of beers available in Hungarian retail. Journal of Food Science and Technology, 54(5), 1158-1167.

Magalhães, L. M., Santos, F., Segundo, M. A., Reis, S. \& Lima, J. (2010). Rapid microplate highthroughput methodology for assessment of Folin-Ciocalteu reducing capacity. Talanta, 83(2), 441-447.

Mitić, S. S., Paunović, D. Đ, Pavlović, A. N., Tošić, S. B., Stojković, M. B. \& Mitić, M. N. (2014). Phenolic Profiles and Total Antioxidant Capacity of Marketed Beers in Serbia. International Journal of Food Properties, 17(4), 908-922.
Pai, T. V., Sawant, S. Y., Ghatak, A. A., Chaturvedi, P. A., Gupte, A. M. \& Desai, N. S. (2015). Characterization of Indian beers: chemical composition and antioxidant potential. Journal of Food Science and Technology, 52(3), 14141423.

Ribeiro, P. A., Queirós, R. B., Delerue-Matos, C. M. \& Ferreira, M. G. (2010). Control and comparison of the antioxidant capacity of beers. Food Research International, 43(6), 1702-1709.

Zapata, P. J., Martínez-Esplá, A., Gironés-Vilaplana, A., Santos-Lax, D., Noguera-Artiaga, L. \& Carbonell-Barrachina, Á. A. (2019). Phenolic, volatile, and sensory profiles of beer enriched by macerating quince fruits. LWT - Food Science and Technology, 103, 139-146. 